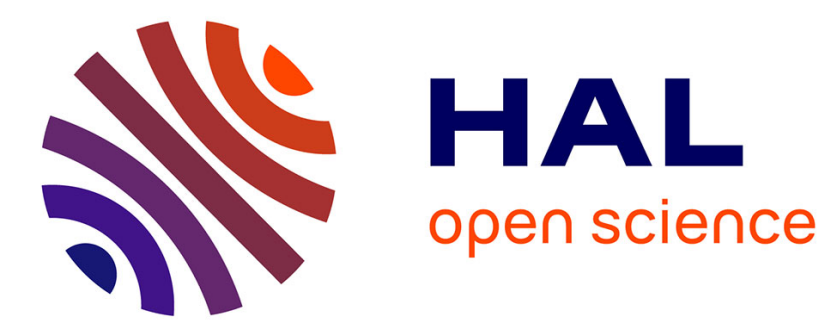

\title{
Unpacking Empowerment in ICT4D Research
}

Priyanka Pandey, Yingqin Zheng

\section{To cite this version:}

Priyanka Pandey, Yingqin Zheng. Unpacking Empowerment in ICT4D Research. 15th International Conference on Social Implications of Computers in Developing Countries (ICT4D), May 2019, Dar es Salaam, Tanzania. pp.83-94, 10.1007/978-3-030-19115-3_8 . hal-02281310

\section{HAL Id: hal-02281310 https://hal.inria.fr/hal-02281310}

Submitted on 9 Sep 2019

HAL is a multi-disciplinary open access archive for the deposit and dissemination of scientific research documents, whether they are published or not. The documents may come from teaching and research institutions in France or abroad, or from public or private research centers.
L'archive ouverte pluridisciplinaire HAL, est destinée au dépôt et à la diffusion de documents scientifiques de niveau recherche, publiés ou non, émanant des établissements d'enseignement et de recherche français ou étrangers, des laboratoires publics ou privés. 


\title{
Unpacking Empowerment in ICT4D Research
}

\author{
Priyanka Pandey ${ }^{1}$ and Yingqin Zheng ${ }^{2}$ \\ Royal Holloway, University of London, Egham, UK \\ ${ }^{1}$ priyanka.pandey.2017@live.rhul.ac.uk \\ 2 yingqin.zheng@rhul.ac.uk
}

\begin{abstract}
Information and communication technology is said to provide paths to empowerment, yet the current ICT4D literature weakly conceptualises how this occurs. This article questions the conceptual alignment between the empowerment concept and the actual empowerment outcome attained through technology. We use Alsop and Heinsohn's measuring empowerment framework and Zimmerman's individual empowerment framework to analyse the missing links between empowerment and technology within current ICT4D research. We argue that research on empowerment in ICT4D needs to 1) be more specific about what type of empowerment takes place; 2) take into account both agency level changes and socioinstitutional structures, 3) consider the dual effect of both empowerment and disempowerment.
\end{abstract}

Keywords: empowerment, disempowerment, structure, agency, ICT4D

\section{Introduction}

The term empowerment is frequently used in ICT4D studies, but often without a clear conceptualization. In some cases, there is a misalignment between the concept of empowerment and the actual findings. Empowerment, as a concept, can entail a wide range of elements that are interconnected and dynamic. A more refined understanding is necessary to unpack the meaning of empowerment and use it not as a sticker but a conceptual or evaluative framework. This paper reviews the current state of the ICT4D literature in the understanding and application of the concept of empowerment as linked with technological adoption. A categorization of empowerment is applied to a core set of ICT4D literature with the objective to firstly, identify how the empowerment concept has been used, in which contexts; and secondly, to review the linkages between claims of empowerment and the actual developmental impact of ICTs in various contexts. We also seek to identify what is missing or underdeveloped in our understanding of empowerment within ICT4D studies.

The various empowerment and technology studies and conceptualizations cited in this paper are from specialist journals on ICT4D, namely Information Technology for Development, Information Technologies \& International Development, and Electronic Journal of Information Systems in Developing Countries; the proceedings of the series of conferences on ICT in developing countries organized by the IFIP WG9.4 and the African Journal of Information Communication and Technology.

The next section gives an overview of the different categories of empowerment and examples from the ICT4D literature. This is followed by a discussion of areas that 
require disambiguation. The paper concludes with recommendations for future research on empowerment in ICT4D.

\section{Categories of Empowerment}

In order to provide a theoretical guidance to the literature review, we apply six categories of empowerment, drawing upon Alsop and Heinsohn's [3] formulation of the empowerment indicators and Zimmerman's [43, 44] conceptualization of the empowerment theory from an individual/psychological level of analysis.

Alsop and Heinsohn give a detailed analysis of the different categories of empowerment; community, political, economic, and cultural and gender and their respective measurement indicators through various developmental projects conducted in Mexico, Ethiopia, Nepal and Honduras. They present an analytic framework that can be used to measure and monitor empowerment processes and outcomes. Their measuring empowerment (ME) framework, rooted in both conceptual discourse and measurement practice, illustrates how to gather data on empowerment and structure its analysis.

Zimmerman gives a nomological network of empowerment at an individual level of analysis. He states that individual empowerment is an open-ended construct that is not easily reduced to a universal set of operational rules and definitions. The measurement of individual or psychological empowerment may be especially difficult because this kind of empowerment '(a) manifests itself in different perceptions, skills, and behaviours across people; (b) different beliefs, competencies, and actions may be required to master various settings; and (c) and may fluctuate over time' [43]. Therefore, the development of population and milieu specific measures of individual empowerment is exigent but crucial to further develop empowerment theory, learn more about how different settings maybe empowering and disempowering and see how empowerment processes change over time.

Alsop and Heinsohn's formulation of the indicators of empowerment comes from a group level analysis such as the family, community or household level. Whilst that helps us recognize differential changes in power at a structural and organizational level, it does not give us a clear direction for an individual or agency level analysis of empowerment which has been seen to occur in most ICT4D empowerment cases we reviewed. Hence Zimmerman's individual empowerment framework fills the missing piece of understanding power changes that take place at an individual level and how it affects not only the individual but also, how it over time brings about larger structural or organizational changes.

In the rest of this section, we briefly introduce the six categories of empowerment. Examples from ICT4D studies are provided in each category. It should be noted that often more than one type of empowerment is discussed in a paper, so the papers are categorized based on the claims made and evidence presented in the paper. 


\subsection{Community Empowerment}

This type of empowerment is defined as expanding the assets and capabilities of poor people to participate in, negotiate with, influence, control and hold accountable the institutions that affects their lives. Studies conducted in the development and other social science fields connote community empowerment with community mobilization and cohesion wherein communities gain the capacity to do things that they want to do and go beyond political or legal permission to participate in the national political system [3, 24, 34, 39]. Within ICT4D studies, studies conducted around microentrepreneurs and GIS technologies have shown to create a certain degree of community empowerment. A study by Corbett and Keller [13] in Indonesia explains how the effects of technology in the form of GIS led to community engagement and mobilization within two communities.

In particular, the results of the study showed that the aspect of being involved in the community mapping process brought about certain levels of community mobilization. Observed indicators of increased (and in some cases decreased) community empowerment capacity included heightened (and lowered) confidence, stronger community cohesion (between old and young) and an improved sense of cultural identity. Individuals appeared to have felt empowered by the skills learned during the routine use of the GIS; some learnt more about their community, some learnt language skills while some got a chance to collaborate with different members of the community. The skills that the individuals acquired also helped alter their social role within the community.

Another example is the case of micro-entrepreneurs in Morocco, where there was an increase in mobilization within communities to work together on their local businesses. ICTs in the form of mobile phones, helped maintaining the network of contacts of buyers by cutting out the middleman and selling traditional handicraft products directly to them [14].

The notion of community empowerment generally involves changes that occur at an individual and organizational level leading to an increase in inclusion, participation and organizational capacity within communities. Technology here becomes a channel through which community mobilization and participation can be achieved. The different functionalities offered by technology create changes through which the community eventually starts to mobilize which leads to a stronger integration of the community. ICT applications that have shown to create a certain degree of community mobilization are geographical information systems, telecentres and internet cafes [3, 14, 26, 36].

\subsection{Psychological Empowerment}

This type of empowerment is broadly defined along the lines of enhancement of capabilities, agency and well-being at an individual level. Most studies of individual empowerment are connoted with psychological empowerment that incorporates the cognitive elements of the individual agency such as intrapersonal and behavioural 
factors of self-esteem, self-perception, self-efficacy, participation and perceived control $[1,3,43,44]$.

According to Zimmerman [44], psychological empowerment is defined as "a cognitive state characterized by a sense of autonomy, competence, and goal internalization". Hence, individual empowerment then becomes multifaceted construct reflecting the three dimensions of being psychologically enabled [43]. Zimmerman's constructs of psychological empowerment theory that includes, interpersonal, interactional and behavioural components can be used as a conceptual model for evaluating psychological empowerment in ICT4D studies. According to Zimmerman [32], the process of empowerment enables individuals to gain control over their lives and master their issues which are important to them and is often associated with developing interventions and creating social change. This would then have further effects on their community life and general lifestyle.

ICT4D studies on empowerment often highlight how technology is able to create individual level changes to the user during its routine use. For example, in the case of Singapore, foreign Vietnamese brides felt an increase in confidence and autonomy through the use of mobile technology. As immigrants from another country they were able to navigate through their transnational identity and accustom to a life in Singapore. Despite the difficulties of acquiring language skills by themselves from home, the mobile phone engendered a sense of autonomy. Certain informal learning channels, such as YouTube videos with English language lessons and beauty tutorials, proved useful. Here we see mobile phones engendering a sense of psychological empowerment for these women. Empowerment came in the form of enhanced capabilities such as English-speaking skills, personal grooming and other educational tutorials, leading to their ability to settle into a new life [31].

Technology here becomes a medium of capability enhancement at an individual level. ICTs in the form of computers, mobile phones or telecentres create changes at an agency level through which individuals feel a change at an interpersonal and behavioural level. This then helps them become capable to navigate through the existing norms and rules to achieve what they want for themselves.

\subsection{Gender Empowerment}

This type of empowerment is achieved when there is a provision of equal rights, voice, freedom of expression, spaces for political and social change and a greater independence/agency to act on one's opportunities and choices for both women and men. This again boils down to having a greater control over one's resources, independence and agency at an individual level. In most ICT4D studies, gender empowerment refers to women having a space for creating social change and being enabled to pursue their choices [6, 16, 19, 20].

ICT4D studies that focus on gender empowerment mainly highlight how women are able to have a higher sense of freedom through technology use. Technology here becomes a medium through which women attain skills and capabilities that offer them with an opportunity or choice set that was not available before. For example, a study conducted by Wheeler [40] on the use of internet cafes by women in Egypt showcases 
how women in strict authoritative states were enabled to create changes in their lives through the access to computers. For women in the Arab world, several obstacles stand in the way of their enablement through ICT, including illiteracy, censorship lack of access, IT knowledge, and lack of technical training. In the case of Egypt, women felt that access to technology in the form of computers and internet-use helped them with their professional development, expand their social network and transform their social and political awareness. Women living in strict authoritative states were able to make friends and connect with people across gender lines and national borders through social networking [6]. Such studies explicate the role of technology in enhancing women's capabilities. Technology here becomes an artefact that creates a space for creating social change for women to gain equal rights and opportunities as men.

\subsection{Cultural Empowerment}

Cultural empowerment seeks to juxtapose narratives, languages and diverse cultural identities, as part of a broader social and educational change that wishes to undermine the hierarchical social divisions and classifications created by the modernist mentality. Empowerment indicators for cultural change include freedom of expression of different cultural identities, narratives, traditions and languages and social and political acceptance of different cultural identities, rituals., traditions, languages and narratives [3, 27, 36].

ICT4D studies that explicate cultural empowerment explain how technology helps bring visibility to the excluded narratives and diverse cultural identities. For instance, in order to bring out the relevance of forgotten indigenous Australian communities, computers and kiosks showcasing the history of such indigenous populations were installed in libraries and museums in order to educate city-dwellers of their presence and importance [28].

Most ICT4D focusing on cultural empowerment use the technology artefact as a medium through which education and knowledge about excluded or forgotten communities, cultures and practices can be imparted to the current population, in order maintain the heritage and importance of such communities. Technology here becomes a conduit through which forgotten narratives and cultural heritage can be brought in the current discourse and dialogue of modern communities.

\subsection{Economic Empowerment}

This type of empowerment ensures the increase, availability and widening of the distribution of basic life-sustaining goods such as food, shelter, health and protection. Economic empowerment highlights the expansion of the range of social and economic choices available to individuals and nations by freeing them from servitude and dependence not only in relation to other people and nation-states but also to the forces of ignorance and human misery $[3,12,18]$.

Alsop and Heinsohn [3] in their choice framework attempt to highlight a subdomain of economic empowerment titled as 'labour'; wherein, opportunity or agency 
enhancement indicators such as increase in literacy levels, acquisition of job specific skills, access to information are assumed to create economic empowerment. Technology here can be assumed to be a channel through which citizens can be given access to education and other world information through computers, which can then prepare them to be eligible for employment which is then assumed to enhance their basic livelihood.

Many ICT4D studies explore how technological adoption enable citizens to achieve an availability of basic goods or an improvement in livelihood, e.g. by using the sustainability livelihood framework without using the concept of empowerment. In the literature review, economic empowerment is often an assumed outcome based on technology adoption. For example, the provision of telecentres in Cape Town helped individuals with access to world information and helped them acquire basic literacy skills but the study did not further investigate if having acquired those skills did actually help them get employed, with a wage that helped increase their livelihood [32]. In order to attain actual economic change where one is able to create a higher accessibility to life sustaining goods, technology needs to integrate through people's existing livelihoods so as to assist them in their day to day struggles of bettering their lives.

\subsection{Political or Structural Empowerment}

This type of empowerment is concerned with civil society mobilization in which citizens' voices are amplified; a mechanism for vertical accountability is created for holding state institutions and service providers accountable for their actions. Political or structural empowerment is etymologically based on a structural shift of power between the state and the citizen. It is about giving power to the citizen to have a transparent relationship with the state wherein the citizen gets to participate in service delivery and policy processes. An actual outcome of political empowerment would inculcate organizational-level change where there is a structural shift of the power that the citizen holds [3, 4, 5, 11, 38].

Most ICT4D empowerment literature does not take into account existing power structures that envelope technology use. While individual level changes are accounted for, broader socio-structural changes are generally not. For example, if a farmer in India chooses to take out a bank loan to finance a lift irrigation system, but the process for obtaining the loan required that he - an illiterate person - complete 20 forms, offer all his land as collateral, and obtain a lawyer to verify that he owned title to the land. The question that arises here is whether the provision of ICT enables the farmer to navigate through these institutional structures in order to attain what he wants, or whether these ICTs further reinforce the existing institutional structures which render the farmer even more powerless than before. Thus, empowerment changes are often considered at the individual level but rarely touch upon how ICTs could help navigate around and shape existing socio-institutional structures [22].

The next section examines in greater detail the missing links within current ICT4D studies such as the lack of emphasis on existing power structures and the disjointment between the empowerment concept and the actual empowerment result. 


\section{Empowerment and ICT4D: Clarifying the Links}

The review of the empowerment literature in ICT4D reveals that the term is sometimes used merely as a sticker to indicate a vague developmental outcome. To have more meaningful discussions on empowerment, there is a need to disentangle the concept and its linkages with ICT adoptions. In this section we discuss two areas of concern from the literature review.

\subsection{Misalignment between the empowerment concept and outcome}

Out of the 23 papers that make an attempt to conceptualize the link between empowerment and technology, a majority of studies have shown a certain degree of individual level empowerment taking place through technology use. Whether it is the use of mobile phones by Vietnamese brides, or the use of internet cafes by women in Egypt; users of technology tend to feel a change in their self-confidence and selfperception due to access to technology or to the information through technology. While the findings of these studies reveal agency level changes, the theorization of the particular empowerment type appears to be disjointed with the actual result of empowerment achieved through technology. For instance, out of the studies that engaged with an individual level analysis, only two studies theorized the various facets of individual empowerment where specific psychological empowerment 'indicators' such as perceived control, self-efficacy, self-confidence, participation, problem solving, coping, and self-determination were explained and analysed in the findings. While in the other studies, either the definition of empowerment was missing, or even if the term was defined it was not distilled within the results of the study.

For instance, in the Ghanaian study of the provision of farming information through radios to farmers [23], empowerment was defined as an increase in autonomy. The study was done to understand how access to farming information affected female farmers in rural Ghana. There were traces of individual empowerment noticed, as the male farmers now had better access to farming information, but the finding of the study mostly focused on women's lack of involvement in the household decision making (or willingness to invest in information delivery technologies). Here the concept of empowerment used was autonomy, but the outcome focused more on the aspect of women's involvement, while there were certain linkages between the two, the evidence and result mostly appeared misaligned.

The literature review shows that ICT4D empowerment studies could benefit from a more refined analysis of empowerment indicators. For instance, in the Egyptian internet cafe case [40], the results revealed that women having access to information and ICTs helped them achieve literacy skills, connect with people from different parts of the world and for some, even gain employment. The findings would be more insightful if explicitly linked with the different indicative factors of psychological empowerment or even economic empowerment, such as the behavioural or intrapersonal factors or percentage of increase in livelihood, types of employment gained etc. 
By clearly conceptualising and identifying the types of empowerment, and evaluating empowerment with specific indicators, ICT4D studies could move beyond general and superficial claims of “empowerment" and acquire deeper understanding on the links between ICT adoption and empowerment.

\subsection{The dual effect of technology: empowerment and disempowerment}

The literature review presented in this paper also indicates the lack of attention to structural conditions. Bar two, the reviewed ICT4D studies failed to address the enveloping structures that permeate ICT use. While agency level changes have been observed to take place not a single study addressed how the existing socio-cultural and socio-institutional structures that envelope ICT use affect the level of empowerment taking place. Furthermore, these studies reveal an undertone of a disempowerment effect that often accompany the empowerment findings. Yet this is rarely reflected upon.

For instance, the installation of computers in the libraries at the University of Zimbabwe were intended to provide computer literacy to students [8]. But due to the first come first basis rule on the use of computers, female students faced reluctance by their male classmates on the use of computers. When asked about their perspectives and experiences around access, the female students spoke about their duties as wives and mothers at home- which they had to fulfil exactly during the same time at which the computers were free-and about the fact that, when they lined up, they ran the risk of being pushed out of the line by the male students. The first-come, first-served rule, which was undoubtedly established by the university management with the intent to guarantee as much "universal access" to both genders as possible, instead became a tool of gender discrimination within the existing system [8]. While the study does reveal the unintended effects of ICT use, it does not however, discuss how the existing patriarchal system was further reinforced with the installation of these computers. Instead of maybe providing a separate time slot for women to use the computers which takes into account of their existing responsibilities, the existing system in which the computers were installed further reinforced the patriarchal structure. Women now were either harassed by men for using the computers or completely missed out the opportunity to use the computers because of their female role as a wife or mother.

In another case, of the GIS use by local communities in rural Indonesia [13], being able to participate in the map making process through the GIS technology did indeed create certain levels of individual empowerment. However, it was also recorded that some informants appeared to lose status through making unwarranted recordings of information. A village elder in one of the communities recorded information about the location and extent of his fruit tree garden as proof of ownership that might be used to insure its inheritance by his descendants, which caused dispute from others in the village. Others in the village contested the truth of his claim. They disputed that the elder used the GIS to try and authenticate a controversial land dispute for his own family's gain, and as a result, his recording from the GIS was deleted; thereby invariably dismissing his right to participate in the GIS. 
The GIS project appeared to reinforce, rather than change, the pre-existing power structures of the community. While agency level changes did occur, they were only felt by those who were already elite and powerful in the community. Due to their existing high status in the community they felt that they had the right to have higher access and participation in the use of technology, thereby excluding the already marginalized groups such as the elderly, minor castes and women even further by not giving them enough space to participate in the GIS. What is observed here, is that while there is individual empowerment taking place for the elite, there is also a simultaneous disempowerment taking place for the marginalized. The installation of mobile phones or computers is taking place in the existing structures of society, so ICTs seem to be reinforcing rather than changing the existing structure.

Marginalized individuals in Indonesia appear to be more powerless than before due to the GIS technology, women studying in the university in Zimbabwe feel more disempowered than before while the elite and powerful individuals in Indonesia and men in Zimbabwe tend to feel psychologically empowered due to the access to technology. Women in Egypt feel psychologically empowered due to access to new information through the internet cafes, but, within the existing authoritative state of rule in Egypt. Vietnamese brides feel an increase in self-confidence due to increase knowledge attained through YouTube tutorials, but that increase in confidence is again grounded on the social approval of their husbands.

Here we see technology creating a dual effect, i.e., within the same community of users, due to existing power structure, we observe parallel effects of empowerment and disempowerment taking place. This is transpiring due to the existing socioinstitutional structures in which ICTs are implanted. The trajectory of ICT use then, is shaped by the very structures of that setting. The dynamics of institutionalized power, such as those vested in systems of political, state and patriarchal control, need to be studied with more depth in order to understand the causes of the parallel disempowerment which takes place alongside the empowerment gained through technology use.

Ibrahim and Alkire [18], in a review of different interpretations of empowerment, argue that all interpretations have an underlying concept of gaining power in some way, which is dependent on agency and the social structures. Kabeer [20] sees empowerment as being fundamentally about power - about the power of people to redefine possibilities and to act on them and providing them the courage to do things they never thought themselves to be capable of. She further adds that "one way of thinking about power is in terms of the ability to make choices: to be disempowered, therefore, implies to be denied choice and the ability to act on that choice" [19]. Empowerment is thus inescapably bound up with the condition of disempowerment, referring to the processes by which those who have been denied the ability to make choices acquire such ability, implying a process of change.

The process of disempowerment is rarely addressed in ICT4D studies. It then becomes crucial to understand how technology not only empowers people but also in certain cases, becomes a medium where the already disempowered become even more powerless. 


\section{Conclusion}

The paper provides a critical literature review on ICT4D studies that use empowerment as a keyword and argues for a clearer and more refined application of the concept in ICT4D research. Empowerment does not take place in a power-free or structure-free space. It is important to address the conceptual chains that link agency and structure to technology use, to gain a holistic perspective on how technology creates a space for empowerment? This will not only help in understanding the relationship between technology and empowerment but also help ICT4D researchers question these chains in terms of coherence and ensure that, the empowerment concept is aligned with its actual technological outcome.

Furthermore, empowerment often comes with the shadow of disempowerment that is neglected in ICT4D research. It is imperative to identify to whom power is getting transferred to, and whether empowerment occurs in a way that reinforces the existing power structure that institutionalizes inequality and marginality. This will help researchers further distil the processes of empowerment and disempowerment occurring through technology use.

\section{$5 \quad$ References}

1. Alao, A., Lwoga, T., and Chigona, W.: Telecentres Use in Rural Communities and Women Empowerment: Case of Western Cape. Information and Communication Technologies for Development, pp.119-134 (2017)

2. Alkire, S., Meinzen-Dick, R., Peterman, A., Quisuimbing, A. R., Seymour, G., \& Vaz, A.: The Women's Empowerment in Agriculture Index. World Development, 52, 71-91 (2013)

3. Alsop, R. and Heinsohn, N.: Measuring empowerment in practice - structuring analysis and framing indicators. Washington, DC. World Bank (2005)

4. Andrews, D.: Capital Mobility and State Autonomy: Toward a Structural Theory of International Monetary Autonomy. International Studies Quarterly 38, 193-218 (1994)

5. Bachrach, $P$ and Baratz, $M$ S.: Two Faces of Power. American Political Science Review 56 (4), 947-952 (1962)

6. Bailur, S., Masiero, S., \& Tacchi, J.: Gender, mobile, and development: The theory and practice of empowerment. Introduction. Information Technologies \& International Development (Special Section), 14, 96-104 (2018)

7. Burrell, J.: Problematic Empowerment: West African Internet Scams as Strategic Misrepresentation. Information Technologies and International Development. MIT Press, 4(4), 15-30 (2008)

8. Buskens, I.: The Importance of Intent: Reflecting on Open Development for Women's Empowerment. Information Technologies and International Development. USC Annennberg, 7(1), 71-76 (2011)

9. Chambers, R.: Participatory Mapping and Geographic Information Systems: Whose Map? Who is Empowered and Who Disempowered? Who Gains and Who Loses? The Electronic Journal of Information Systems in Developing Countries. 25(1), 1-11 (2006) 
10. Chew, H., Ilavarasan, V. and Levy, M.: Mattering Matters: Agency, Empowerment, and Mobile Phone Use by Female Microentrepreneurs. Information Technology for Development. 21(4), 523-542 (2015)

11. Clegg SR. Frameworks of power.: London: Sage Publications (1989)

12. Combaz, E. and Mcloughlin, C.: Voice, empowerment and accountability: Topic guide. Birmingham, UK: GSDRC, University of Birmingham. (2014)

13. Corbett, J and Keller, P.: Empowerment and Participatory Geographic Information and Multimedia Systems: Observations from Two Communities in Indonesia. Information Technologies and International Development. MIT Press, 2(2), 25-44 (2004)

14. Davis, S.: Empowering Women Weavers? The Internet in Rural Morocco. Information Technologies and International Development. 4(2), 17-23 (2008)

15. Dwyer, N., Basu, A and Marsh, S.: Reflections on Measuring the Trust Empowerment Potential of a Digital Environment. IFIP International Conference on Trust Management. AICT 401(2013)

16. Guérin, I., Kumar, S., and Agier, I.: Women's Empowerment: Power to Act or Power over Other Women? Lessons from Indian Microfinance. Oxford Development Studies. 41(1), S76-S94 (2013)

17. Haque, A. and Mantode, K.: Governance in the Technology Era: Implications of Actor Network Theory for Social Empowerment in South Asia. Grand Successes and Failures in IT. Public and Private Sectors, pp.375-390. International Working Conference on Transfer and Diffusion of IT. 390, 375-390 (2017)

18. Ibrahim, S and Alkire, S.: Agency and Empowerment: a proposal for international comparable indicators. OPHI Working Paper, Oxford (2007)

19. Kabeer, N.: The Conditions and Consequences of Choice: Reflection on the Measurement of Women's Empowerment. UNRISD Discussion Paper 108. United Nations Research Institute for Social Development, Geneva (1999b)

20. Kabeer, N.: Resources, agency, achievements: Reflections on the measurement of women's empowerment. Development and change, 30(3), 435-464 (1999a)

21. Kanter MK.: Power failure in management circuits. Harvard Business Review. 57(4):65-75 (1979)

22. Kleine, D.: ICT4What? Using the Choice Framework to Operationalise the Capabilities Approach to Development. Journal of International Development. 22, 674-692 (2010)

23. Kwapong, O.: An Empirical Study of Information and Communication Technology for Empowerment of Rural Women in Ghana. African Journal of Information \& Communication Technology. 4(3), (2009)

24. Laverack, G.: Improving Health Outcomes through Community Empowerment: A Review of the Literature. Journal of Health, Population and Nutrition. 24(1), 113-120 (2006)

25. Maier, S.: Women's Empowerment and the Information Society. Information Technologies and International Development. MIT Press, 4(2), 1-2 (2008)

26. Maier, S. and Nair-Reichert, U.: Empowering Women Through ICT-Based Business Initiatives: An Overview of Best Practices in E-Commerce/E-Retailing Projects. Information Technologies and International Development. 4(2), 43-60 (2008)

27. Markovich, D.: Making Identity Visible: The Case of the "Museum in a Suitcase" in Handbook of Research on Didactic Strategies and Technologies for Education: Incorporating Advancements. IGI Global. 426-435(2013) 
28. McClellan, D and Tanner, K.: Knowledge Discovery Empowering Australian Indigenous Communities. Information Technologies and International Development. USC Annennberg, 7(2), 31-46 (2011)

29. Mohapi, M. and Njenga, K.: Conceptualising the Effect of the Black Economic Empowerment Score-Card on IT Governance. The Electronic Journal of Information Systems in Developing Countries. 54(1), 1-44 (2012)

30. Moyi, E.: Networks, information and small enterprises: New technologies and the ambiguity of empowerment. Information Technology for Development. IOS Press. 10, 221232 (2003)

31. Nguyen, H., Chib, A and Mahalingam, R.: Mobile phones and gender empowerment: Negotiating the essentialist-aspirational dialectic. Information Technologies \& International Development (Special Section). 13, 171-185 (2017)

32. Osman, M. and Tanner, M.: The Influence of Telecentre Components on the Psychological Empowerment of Underserved Community Members in the Western Cape, South Africa. The Electronic Journal of Information Systems in Developing Countries. 81(1), 129 (2017)

33. Paramentier, MJ and Huyer, S.: Female Empowerment and Development in Latin America: Use Versus Production of Information and Communications Technology. Information Technologies and International Development. MIT Press. 4(3) 13-20 (2008)

34. Perkins, D.D., Brown, B.B. and Taylor, R.B.: The ecology of empowerment: Predicting participation in community organizations. Journal of Social Issues. 52(1), 85-110 (1996)

35. Rahman, M.: Peace and Conflict Monitor, ICT Governance vs. Community Empowerment: Grassroots Evidence from Bangladesh. IFIP International Conference on Critical Information Infrastructure Protection. 328 (2010)

36. Sadan, E.: Theories of Power. In E. Sadan (Ed.), Empowerment and Community Planning: Theory and practice of people-focused social solutions. Tel Aviv: Hakibbuty Hamenchad Publishers (2004)

37. Sterling, R.: Book review on African Women and ICTs: Investigating Technology, Gender and Empowerment. Information Technologies and International Development. MIT Press, 7(1), 79-82 (2011)

38. Swank, D.: Politics and the Structural Dependence of the State in Democratic Capitalist Nations. American Political Science Review. 86 (1) 38-54 (1992)

39. Wallerstein N.: Empowerment and health: the theory and practice of community change. Community Development Journal. 28, 218-227 (1993)

40. Wheeler, D.: Empowerment Zones? Women, Internet Cafés, and Life Transformations in Egypt. Information Technologies and International Development. 4(2), 89-104 (2007)

41. World Bank.: What is empowerment? Poverty.net. Poverty reduction and Equity (2016)

42. Zheng, Yingqin.: Different Spaces for eDevelopment: what we can learn from the capability approach, Information Technology for Development. 15(2), 66-82 (2009)

43. Zimmerman, M.A.: Psychological Empowerment: Issues and Illustrations. American Journal of Community Psychology. 23(5), 581-599 (1995)

44. Zimmerman, M.A.: Empowerment Theory: Psychological, Organizational and Community Levels of Analysis. In Rappaport, J. \& Seldman, E. (Eds.). Handbook of Community Psychology. New York: Springer. 43-63(2000) 